\title{
PENGARUH FASILITAS SEKOLAH TERHADAP HASIL BELAJAR AKUNTANSI DENGAN LINGKUNGAN SOSIAL SEBAGAI PEMODERASI
}

\author{
Nik Amah \\ Angga Dwi Nugroho \\ Pendidikan Akuntansi IKIP PGRI MADIUN \\ sigmaku87@gmail.com
}

\begin{abstract}
This study aimed to examine the effect of school facilities for learning outcomes accounting class XI and XII IPS 1 MAN 1 Madiun with the social environment as moderating. Research conducted at the school MAN 1 Madiun with a sample size of 60 students. sample which all of the study population as sample. Data collected by questionnaire. Data were analyzed using regression analysis of the moderation that is testing the absolute value of the difference.The results showed that school facilities as well as the social environment is partially significant effect on learning outcomes of students of class XI and XII IPS 1 MAN 1 Madiun. The absolute value of the difference test results showed that the social environment variable is vaiabel moderating influence that is capable of strengthening the school facilities on student learning outcomes. School facilities and social environments simultaneously influence in student learning outcomes.
\end{abstract}

Keywords: school facilities, social environment, learning outcomes

Abstrak: Penelitian ini bertujuan untuk menguji pengaruh fasilitas sekolah terhadap hasil belajar akuntansi siswa kelas XI dan XII IPS 1 MAN 1 Madiun dengan lingkungan sosial sebagai pemoderasi. Penelitian dilaksanakan di sekolah MAN 1 Madiun dengan jumlah sampel sebanyak 60 siswa. Teknik pengambilan sampel yaitu sampel jenuh dimana semua populasi penelitian menjadi sampel penelitian. Pengumpulan data dilakukan dengan instrumen kuesioner. Teknik analisis data menggunakan analisis regresi moderasi yaitu uji nilai selisih mutlak.

Hasil penelitian menunjukan bahwa fasilitas sekolah maupun Lingkungan sosial secara parsial berpengaruh signifikan terhadap hasil belajar siswa kelas XI dan XII IPS 1 MAN 1 Madiun. Hasil uji nilai selisih mutlak menunjukan bahwa variabel lingkungan sosial merupakan vaiabel pemoderasi yang mampu memperkuat pengaruh fasilitas sekolah terhadap hasil belajar siswa. Secara simultan variabel fasilitas sekolah dan lingkungan sosial bepengaruh terhadap hasil belajar siswa.

Kata Kunci: fasilitas sekolah, lingkungan sosial, hasil belajar

Pendidikan adalah hal mutak dibutuhkan oleh manusia. Untuk hidup manusia tidak hanya cukup tumbuh dan berkembang dengan dorongan insting saja, melainkan perlu bimbingan dan dorongan dari luar dirinya. Bimbingan dan dorongan dari luar inilah yang bisa kita sebut dengan pendidikan. Pendidikan tidak hanya dapat diperoleh dari jalur formal (di bangku sekolah dan perkuliahan), namun juga nonformal (seperti halnya lembaga kursus, 
kelompok belajar, Taman Pendidikan Al Quran, Sekolah Minggu), serta jalur informal (sebagai contoh pendidikan keluarga dan lingkungan). Pendidikan adalah proses yang dialami seseorang untuk dapat mengeksplor potensi dan bakat diri, meningkatkan kecerdasan, keterampilan, mempertinggi budi pekerti, memperkuat kepribadian, meningkatkan kekuatan spiritual keagamaan dan mempertebal semangat kebersamaan agar dapat membangun diri sendiri dan bersama-sama membangun bangsa dan negara.

Menurut Undang-undang Republik Indonesia No. 20 tahun 2003 tentang Sistem Pendidikan Nasional Bab I pasal 1 menyatakan:

"Pendidikan merupakan usaha sadar dan terencana untuk mewujudkan suasana belajar dan proses pembelajaran agar peserta didik secara aktif mengembangkan potensi dirinya untuk memiliki kekuatan spiritual keagamaaan, pengendalian diri, kepribadian, kecerdasan, akhlak mulia, serta keterampilan yang diperlukan dirinya, masyarakat, bangsa, dan negara.”

Keberhasilan seseorang dalam hal pendidikan akan sangat terkait dengan hasil belajar yang dicapainya. Dimana hasil belajar ini tercermin pada nilai atau ukuran lainnya yang mencerminkan tingkat ketercapaian seseorang dalam hal pendidikan. Menurut Suprijono (2011: 5-6) hasil belajar adalah pola-pola perbuatan, nilai-nilai, pengertian-pengertian, sikapsikap, apresiasi dan keterampilan. Hasil belajar mencakup kemampuan kognitif, afektif, dan psikomotorik.

Hasil belajar seseorang akan dipengaruhi oleh faktor-faktor baik intern (dari dalam diri) maupun ekstern (dari luar diri). Faktor internal tersebut diantaranya adalah faktor fisiologis dan psikologis siswa. Sedangkan faktor eksternal meliputi faktor lingkungan dan faktor instrumental. Lingkungan memberikan pengaruh yang sangat besar dalam pembentukan berbagai sifat, sikap, perasaan, pemikiran dan unsur psikologis lainnya yang sering juga disebut sebagai kepribadian (Rusman, 2013:24).

Pada pendidikan formal (sekolah) lingkungan sosial adalah faktor eksternal yang bersinggungan dengan peserta didik yang akan mendukung hasil belajarnya. Menurut Muhibbin Syah (2012 : 154) lingkungan sosial sekolah seperti para guru, para staf administrasi, dan teman - teman sekelas dapat mempengaruhi semangat belajar siswa. Semakin baik lingkungan sekolah maka semakin mendorong siswa untuk belajar lebih giat sehingga mampu meningkatkan hasil belajar. Djamarah dan Zain (2008 : 117) berpendapat lingkungan merupakan bagian dari kehidupan anak didik. Selama hidup anak tidak bisa menghindarkan diri dari lingkungan alami dan lingkungan sosial budaya. Keduanya mempunyai pengaruh terhadap belajar anak didik di sekolah. 
Faktor lain yang dapat menunjang hasil belajar siswa yaitu faktor instrumen seperti halnya fasilitas sekolah. Mulyasa (2011 : 49) berpendapat bahwa fasilitas adalah peralatan atau perlengkapan yang secara langsung dipergunakan dan untuk menunjang proses pendidikan, khususnya proses belajar mengajar, seperti gedung ruang, meja, kursi, serta alat alat media pembelajaran. Menurut Sopiatin (2010: 73) fasilitas merupakan sarana dan prasarana yang harus tersedia untuk melancarkan kegiatan pendidikan di sekolah.

Beberapa studi mengenai pengaruh lingkungan dan fasilitas sekolah. Permana (2014) melakukan penelitian di kelas XI IPS pada pembelajaran IPS Geografi di SMA N 2 Palu. Kesimpulan yang diperoleh adalah ada pengaruh yang signifikan antara pengaruh lingkungan sosial terhadap hasil belajar siswa kelas XI IPS pada pembelajaran IPS Geografi di SMA Negeri 2 Palu. Sedangkan penelitian Hidayat (2013) yang berjudul "Pengaruh disiplin dan fasilitas sekolah terhadap hasil belajar siswa”. Hidayat (2013) menyimpulkan bahwa terdapat pengaruh fasilitas sekolah terhadap hasil belajar Geografi siswa kelas XI IPS SMA N 10 Sijunjung.

Peneliti menangkap fenomena yang terjadi pada salah sekolah di sekitar peneliti yaitu MAN 1 Madiun. Gedung sekolah MAN 1 Madiun pada awalnya berlokasi di Jl. Barito no.13 yang lokasinya berada di tempat yang lalu lintasnya tidak terlalu ramai. Kemudian Gedung sekolah MAN 1 Madiun berpindah ke Jl. Soekarno Hatta no.68, yang berada di kawasan yang lalu lintasnya cukup ramai dan dekat dengan Universitas Islam Indonesia Madiun. Perpindahan lokasi sekolah ini berarti bahwa selain sekolah memiliki gedung baru dengan fasilitas-fasilitas baru tentu saja lingkungan sosial di sekitar sekolah juga baru. Fasilitas baru pada sekolah ini memungkinkan siswa untuk lebih giat belajar hingga mencapai hasil belajar yang baik ataukah justru sebaliknya membuat siswa kurang bersemangat belajar karena kelengkapan fasilitas sekolah di lokasi yang baru belum memadai. Selanjutnya lingkungan sosial jika lingkungan sosial pada sekolah baru baik maka akan memungkinkan peningkatan hasil belajar. Penulis memiliki pemikiran bahwa fasilitas sekolah yang memadai akan mendukung kegiatan belajar dalam suatu pendidikan yang pada akhirnya dapat mempengaruhi hasil belajar. Lingkungan sosial sekolah yang baik akan memperkuat pengaruh fasilitas sekolah dalam meningkatkan hasil belajar siswa.

Berdasarkan latar belakang masalah yang telah dipaparkan sebelumnya serta adanya fenomena yang menarik untuk dikaji maka penulis mengadakan penelitian yang bertujuan untuk mengetahui pengaruh fasilitas sekolah terhadap hasil belajar siswa kelas XI dan XII IPS MAN 1 Madiun Tahun Ajaran 2014/2015 dengan lingkungan sosial sebagai 
pemoderasi. Sesuai dengan tujuan penelitian, maka Hipotesis yang diajukan oleh peneliti adalah sebagai berikut:

Ha1 = Fasilitas sekolah berpengaruh terhadap hasil belajar siswa kelas XI dan XII IPS MAN 1 Madiun.

Ha2 = lingkungan sosial mampu memperkuat pengaruh fasilitas sekolah terhadap hasil belajar siswa kelas XI dan XII IPS MAN 1 Madiun.

\section{METODE}

Penelitian ini merupakan penelitian kuantitatif yang dikembangkan dengan model regresi moderasi. Penelitian kuantitatif dapat diartikan sebagai metode penelitian yang berlandaskan pada filsafat positivisme, digunakan untuk meneliti pada populasi atau sampel tertentu, teknik pengambilan sampel dilakukan dengan menggunakan teknik sampling jenuh, pengumpulan data menggunakan instrumen penelitian, analisis data bersifat kuantitatif/statistik dengan tujuan untuk menguji hipotesis yang telah ditetapkan (Sugiyono, 2010: 14).

Populasi adalah keseluruhan subjek dari penelitian (Arikunto, 2010: 173). Populasi yang digunakan dalam penelitian adalah siswa kelas XI dan XII IPS MAN 1 MADIUN sebanyak 60 siswa. Teknik pengambilan sampel menggunakan teknik sampling jenuh, yaitu teknik penentuan sampel bila semua anggota populasi digunakan sebagai sampel (Sugiyono, 2010: 124) sehingga jumlah sampel sebesar 60 siswa.

Jenis data dalam penelitian ini adalah jenis data primer, karena data diperoleh langsung dari obyek penelitian. Sumber data yang digunakan yaitu responden yang meliputi siswa kelas XI dan XII IPS MAN 1 Madiun. Teknik pengumpulan data primer menggunakan kuesioner atau angket tentang lingkungan sosial sekolah dan fasilitas sekolah, serta pengumpulan data lain yaitu nilai ujian akhir semester untuk mengukur hasil belajar siswa. Instrumen merupakan alat yang akan digunakan untuk mengumpulkan data, dalam penelitian ini instrumen yang digunakan adalah angket (kuesioner) dengan lima alternatif jawaban yang dikembangkan menurut skala Likert. Berikut ini disampaikan kisi - kisi instrumen penelitian. Kisi - kisi ini dijadikan dasar sebagai pembuatan kuisioner.

\begin{tabular}{|c|c|c|c|}
\hline No & Variabel & Definisi Operasional & Indikator \\
\hline 1. & Lingkungan sosial & $\begin{array}{l}\text { Interaksi sosial yang terjadi } \\
\text { antara siswa dengan siswa, } \\
\text { siswa dengan kelompok dan } \\
\text { siswa dengan guru. }\end{array}$ & $\begin{array}{l}\text { - Peniruan } \\
\text { - Sugesti } \\
\text { - Identifikasi } \\
\text { - Simpati }\end{array}$ \\
\hline
\end{tabular}




\begin{tabular}{|l|l|l|l|}
\hline 2. & Fasilitas Sekolah & $\begin{array}{l}\text { Sarana dan prasarana yang } \\
\text { secara langsung digunakan } \\
\text { untuk menunjang proses } \\
\text { pendidikan. }\end{array}$ & $\begin{array}{l}\text { - } \\
\text { - Perlengunan sekolah } \\
\text { - Media pengajaran }\end{array}$ \\
& & & - Sarana perpustakaan \\
& & $-\begin{array}{l}\text { Pengelolaan laboratorium } \\
\text { Kantin sekolah }\end{array}$ \\
\hline 3. & Hasil Belajar & $\begin{array}{l}\text { Hasil dari suatu kegiatan yang } \\
\text { telah dikerjakan atau } \\
\text { diciptakan baik secara } \\
\text { individu maupun kelompok. }\end{array}$ & $\begin{array}{l}\text { Nilai rapor siswa Kelas XI } \\
\text { dan XII Semester II } \\
\text { MAN 1 Madiun Tahun } \\
\text { Pelajaran 2014/2015 }\end{array}$ \\
\hline
\end{tabular}

Untuk mendapatkan data yang akurat maka peneliti melakukan uji instruments yang meliputi uji reliabilitas dan validitas. Teknik analisis data yang digunakan adalah analisis regresi moderasi dengan uji nilai selisih mutlak. Pengujian validitas menggunakan korelasi bivariat dimana pengambilan keputusan valid apabila $\mathbf{r}_{\text {hitung }}>\mathbf{r}_{\text {tabel }}$ dan tidak valid jika $\mathbf{r}_{\text {hitung }}>$ $\mathrm{r}_{\text {tabel. }}$

\section{Uji Validitas Fasilitas Sekolah}

Berdasarkan hasil pengolahan data diperoleh hasil berikut:

\begin{tabular}{|l|l|l|l|}
\hline Pernyataan & rhitung & rtabel & Keterangan \\
\hline Pernyataan 1 & 0,617 & 0,254 & Valid \\
\hline Pernyataan 2 & 0,496 & 0,254 & Valid \\
\hline Pernyataan 3 & 0,586 & 0,254 & Valid \\
\hline Pernyataan 4 & 0,463 & 0,254 & Valid \\
\hline Pernyataan 5 & 0,652 & 0,254 & Valid \\
\hline Pernyataan 6 & 0,622 & 0,254 & Valid \\
\hline Pernyataan 7 & 0,511 & 0,254 & Valid \\
\hline Pernyataan 8 & 0,633 & 0,254 & Valid \\
\hline Pernyataan 9 & 0,585 & 0,254 & Valid \\
\hline Pernyataan 10 & 0,657 & 0,254 & Valid \\
\hline Pernyataan 11 & 0,694 & 0,254 & Valid \\
\hline Pernyataan 12 & 0,581 & 0,254 & Valid \\
\hline
\end{tabular}

Berdasarkan tabel di atas dapat diketahui bahwa semua item pernyataan variabel fasilitas sekolah dinyatakan valid karena $r_{\text {hitung }}$ untuk semua pernyataan lebih besar dari $r_{\text {tabel. }}$. 


\section{Uji Validitas Fasilitas Sekolah}

Berdasarkan hasil pengolahan data diperoleh hasil berikut:

\begin{tabular}{|l|l|l|l|}
\hline Pernyataan & rhitung & rtabel & Keterangan \\
\hline Pernyataan 1 & 0,755 & 0,254 & Valid \\
\hline Pernyataan 2 & 0,586 & 0,254 & Valid \\
\hline Pernyataan 3 & 0,639 & 0,254 & Valid \\
\hline Pernyataan 4 & 0,464 & 0,254 & Valid \\
\hline Pernyataan 5 & 0,647 & 0,254 & Valid \\
\hline Pernyataan 6 & 0,601 & 0,254 & Valid \\
\hline Pernyataan 7 & 0,521 & 0,254 & Valid \\
\hline Pernyataan 8 & 0,667 & 0,254 & Valid \\
\hline Pernyataan 9 & 0,668 & 0,254 & Valid \\
\hline Pernyataan 10 & 0,662 & 0,254 & Valid \\
\hline Pernyataan 11 & 0,740 & 0,254 & Valid \\
\hline Pernyataan 12 & 0,566 & 0,254 & Valid \\
\hline
\end{tabular}

Berdasarkan tabel di atas dapat diketahui bahwa semua item pernyataan variabel lingkungan sosial dinyatakan valid karena $r_{\text {hitung }}$ untuk semua pernyataan lebih besar dari $r_{\text {tabel}}$.

\section{Uji Reliabilitas}

Uji reliabiltas menggunakan niai Cronbach Alpha. Jika nilai Cronbach Alpha > 0,6 maka dinyatakan reliabel dan jika Cronbach Alpha < 0,6 maka instrumen dikatakan tidak reliabel (Siregar, 2011: 89). Hasil uji reliabilitas adalah sebagai berikut:

\begin{tabular}{|l|l|l|}
\hline Variabel & Nilai Alpha & Keterangan \\
\hline Fasilitas Sekolah & 0,747 & Reliabel \\
\hline Lingkungan Sosial & 0,754 & Reliabel \\
\hline
\end{tabular}

Dari tabel di atas terlihat bahwa instrumen untuk variabel fasilitas sekolah maupun lingkungan sosial memiliki nilai alpha > 0,6 sehingga disimpulkan semua instrumen reliabel.

\section{HASIL DAN PEMBAHASAN}


Penelitian ini dianalisis dengan regresi moderasi yang dapat dije;askan dengan persamaan berikut:

\section{Hasil belajar $=\mathbf{a}+$ b1Zfasilitas sekolah + b2Zlingkungan sosial + b3ABSX1_X2 + e}

Untuk menguji pengaruh moderasi peneliti menggunakan uji nilai selisih mutlak. Sebelum dianalisis dengan regresi moderasi, peneliti melakukan uji asumsi klasik terlebih dulu yaitu meliputi uji normalitas, uji multikolinearitas, uji autokorelasi dan uji heteroskedastisitas. Berdasarkan hasil pengolahan data untuk uji normalitas diperoleh hasil Pplot sebagai berikut:

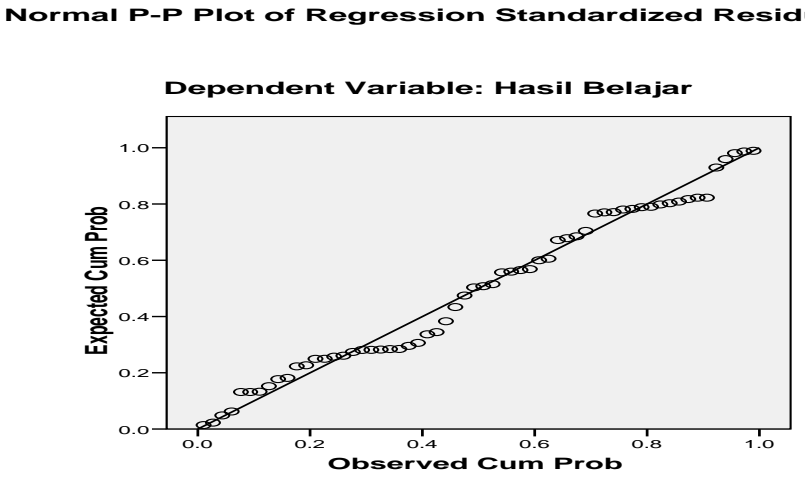

\section{Gambar 1. Hasil Uji Normalitas dengan P-plot}

Hasil P-plot menunjukan bahwa setiap pancaran data residual berada di sekitar garis lurus melintang, maka dapat disimpulkan bahwa data tersebut berdistribusi normal. Hasil pengolahan data dengan menggunakan uji One Sample Kolmogorof-Smirnov diperoleh hasil sebagai berikut:

One-Sample Kolmogorov-Smirnov Test

\begin{tabular}{|c|c|c|}
\hline & & $\begin{array}{c}\text { Unstandardized } \\
\text { Residual } \\
\end{array}$ \\
\hline \multirow[t]{6}{*}{$\mathrm{N}$} & & 60 \\
\hline & Mean & 0,0000000 \\
\hline & Std. Deviation & 6,84017416 \\
\hline & Absolute & 0,099 \\
\hline & Positive & 0,099 \\
\hline & Negative & $-0,072$ \\
\hline \multicolumn{2}{|c|}{ Kolmogorov-Smirnov Z } & 0,763 \\
\hline \multicolumn{2}{|c|}{ Asymp. Sig. (2-tailed) } & 0,605 \\
\hline
\end{tabular}


Hasil pada tabel di atas menunjukkan nilai signifikansi residual sebesar 0,605 berarti lebih besar dari (>) 0,05 sehingga dapat disimpulkan data berdistribusi normal.

Uji multikolinieritas dilakukan dengan menggunakan nilai tolerance dan VIF (Variance Inflation Factor) pada model regresi. Jika nilai tolerance > 0,1 dan VIF (Variance Inflation Factor $<10$ maka model regresi tidak memiliki gejala atau tidak terjadi multikolinieritas (Priyatno, 2009: 56). Hasil uji multikolinearitas dapat dilihat hasilnya sebagai berikut :

Tabel Hasil Uji Multikolinearitas

\begin{tabular}{|c|c|c|c|}
\hline \multirow{2}{*}{ Variabel } & \multicolumn{2}{|c|}{ Collinearity Statistics } & \multirow{2}{*}{ Keterangan } \\
\hline & Tolerance & VIF & \\
\hline Zscore: fasilitas sekolah (X1) & 0,968 & 1,033 & Tidak ada Multikolinearitas \\
\hline Zscore: lingkungan sosial (X2) & 0,968 & 1,033 & Tidak ada Multikolinearitas \\
\hline ABSX1_X2 & 0,992 & 1,008 & Tidak ada Multikolinearitas \\
\hline
\end{tabular}

Hasil pengujian multikolinearitas menunjukkan bahwa nilai tolerance masingmasing variabel berada di atas 0,1 dan nilai VIF masing-masing variabel berada di bawah 10 . Dari hasil uji multikolinearitas dapat disimpulkan bahwa secara keseluruhan tidak terdapat multikoliniearitas pada model regresi moderasi.

Pengujian heteroskedastisitas dilakukan dengan uji korelasi Spearman. Kriteria pengujian jika nilai signifikansi korelasi antara variabel independen dengan residual lebih dari 0,05 maka tidak terjadi heteroskedastisitas. Berikut hasil uji korelasi Spearman:

Tabel Hasil Uji Heteroskedastisitas

\begin{tabular}{|ll|l|l|l|}
\hline & & $\begin{array}{l}\text { Fasilitas } \\
\text { Sekolah }\end{array}$ & $\begin{array}{l}\text { Lingkungan } \\
\text { Sosial }\end{array}$ & ABSX1_X2 \\
\hline Unstandarized residual $\quad$ Sig.(2-tailed) & 0,930 & 0,654 & 0,771 \\
\hline
\end{tabular}

Dari hasil pengujian terlihat bahwa nilai signifikansi korelasi antara variabel independen dengan residual semuanya di atas $(>0,05)$. Hal tersebut berarti bahwa pada model regresi moderasi tidak terdapat heteroskedastisitas.

Uji autokorelasi pada model penelitian dilakukan dengan menggunakan uji DurbinWatson. Jika nilai D-W terletak di antara nilai dU dan 4-dU, maka bebas dari autokolerasi. Hasil pengujian autokorelasi adalah sebagai berikut: 
Tabel Hasil Uji Autokorelasi

\begin{tabular}{|c|c|c|c|c|}
\hline Durbin Watson & Kriteria & $\mathrm{du}$ & 4-du & Keterangan \\
\hline 1,966 & $\mathrm{du}<\mathrm{d}<4-\mathrm{du}$ & 1,689 & 2,311 & $\begin{array}{c}\text { Tidak terjadi } \\
\text { autokorelasi }\end{array}$ \\
\hline
\end{tabular}

Dari hasil pengujian di atas terlihat bahwa nilai dw terletak di antara nilai du dan 4du $(1,689<1,966<2,311)$. Hal tersebut dapat disimpulkan bahwa tidak terjadi autokorelasi pada model regresi moderasi.

Tabel Hasil Uji Koefisien Determinasi

\begin{tabular}{|l|l|r|r|r|}
\hline Model & R & R Square & $\begin{array}{r}\text { Adjusted } \\
\text { R Square }\end{array}$ & $\begin{array}{r}\text { Std. Error of } \\
\text { the Estimate }\end{array}$ \\
\hline 1 & 0,633 & 0,400 & 0,368 & 7,021 \\
\hline
\end{tabular}

Dari tabel di atas diketahui bahwa nilai adjusted $\mathrm{R}^{2}$ sebesar $40 \%$ yang berarti bahwa variabilitas hasil belajar dapat dijelaskan oleh variabel Zfasilitas sekolah dan Zlingkungan sosial serta ABSX1_X2 sekitar 40\% sedangkan sisanya sebesar 60\% dijelaskan oleh variabel lain di luar variabel yang diteliti. Hal ini disebabkan adanya banyak faktor yang diduga mempengaruhi hasil belajar siswa kelas XI dan kelas XII IPS 1 MAN 1 Madiun bukan hanya dari faktor intern saja namun juga faktor ekstern. Sebagaimana yang diungkapkan Slameto (2010) bahwa hasil belajar dapat dipengaruhi oleh kesehatan, cacat tubuh, intelegensi, perhatian, minat, disiplin, dan motivasi yang merupakan faktor internal siswa, serta lingkungan keluarga, lingkungan sekolah, dan sebaya yang merupakan faktor eksternal. Selanjutnya hasil pengujian hipotesis ditunjukkan pada tabel hasil uji $\mathrm{F}$ statistik dan tabel hasil uji t statistic sebagai berikut:

Tabel Hasil Uji F Statistik

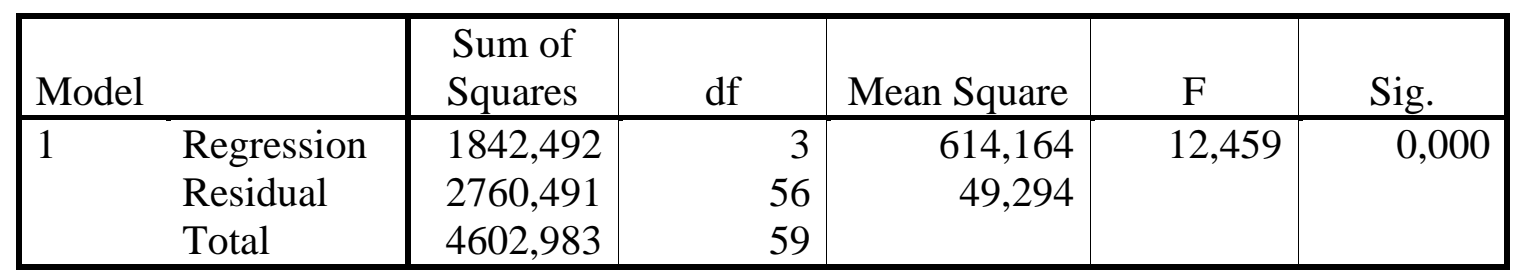

Tabel di atas menunjukan tingkat signifikansi $0,000(<0,05)$ sehingga dapat disimpulkan bahwa variabel independen Zfasilitas sekolah dan Zlingkungan sosial serta ABSX1_X2 secara simultan berpengaruh terhadap variabel hasil belajar. Fasilitas sekolah biasanya identik dengan sarana prasana yang tersedia di sekolah. Fasilitas sekolah yang baik akan memberikan dampak bagi siswa untuk lebih semangat belajar. Selain itu fasilitas sekolah yang lengkap dan memadai akan memberikan kemudahan serta mendukung kemauan siswa 
dalam belajar. Perpindahan lokasi sekolah MAN 1 Madiun berarti bahwa selain sekolah memiliki gedung baru, fasilitas-fasilitas yang ada di sekolah juga baru. Fasilitas sekolah ini memungkinkan siswa untuk lebih giat belajar hingga mencapai hasil belajar yang baik. Demikian juga dengan lingkungan sosial sekolah MAN 1 Madiun juga baru yang awalnya berlokasi di Jl. Barito no.13 berada di tempat yang lalu lintasnya tidak terlalu ramai. Kemudian Gedung sekolah MAN 1 Madiun berpindah ke J1. Soekarno Hatta no.68, yang berada di kawasan yang lalu lintas dan dekat dengan Universitas Islam Indonesia Madiun. Lingkungan sosial sekolah MAN 1 Madiun yang dekat dengan kawasan lalu lintas memberikan kemudahan akses bagi siswa untuk berangkat ataupun pulang sekolah. Selain itu lingkungan sekolah MAN 1 Madiun yang dekat dengan Universitas Islam Indonesia Madiun merupakan keuntungan tersendiri karena iklim kondusif untuk belajar telah terbentuk. Lingkungan sosial dengan iklim kondusif akan sangat mendukung siswa dalam belajar yang pada akhirnya akan berpengaruh pada hasil belajar siswa. Hasil penelitian ini mendukung penelitian Pakpahan (2013) yaitu fasilitas belajar dan lingkungan belajar secara simultan berpengaruh terhadap prestasi belajar siswa SMK Raksana 2 Medan. Selain itu juga mendukung penelitian Permana (2014) yang menyatakan bahwa lingkungan sosial berpengaruh terhadap hasil belajar siswa XI IPS pada pembelajaran IPS Geografi.

Tabel Hasil Uji t Statistik (dengan Uji Nilai Selisih Mutlak)

\begin{tabular}{|c|c|c|c|c|c|c|}
\hline \multirow{2}{*}{\multicolumn{2}{|c|}{$\begin{array}{l}\text { Mode } \\
1\end{array}$}} & \multicolumn{2}{|c|}{$\begin{array}{c}\text { Unstandardized } \\
\text { Coefficients }\end{array}$} & \multirow{2}{*}{$\begin{array}{c}\text { Standardized } \\
\text { Coefficients } \\
\text { Beta } \\
\end{array}$} & \multirow[b]{2}{*}{$\mathrm{t}$} & \multirow[b]{2}{*}{ Sig. } \\
\hline & & B & $\begin{array}{l}\text { Std. } \\
\text { Error }\end{array}$ & & & \\
\hline \multirow[t]{4}{*}{1} & \multirow{3}{*}{$\begin{array}{l}\text { (Constant) } \\
\text { ZFasilitas Sekolah } \\
\text { ZLingkungan Sosial }\end{array}$} & 69,478 & 1,593 & & 43,619 & 0,000 \\
\hline & & 2,748 & 0,929 & 0,311 & 2,959 & 0,005 \\
\hline & & 3,648 & 0,929 & 0,413 & 3,926 & 0,000 \\
\hline & ABSX1_X2 & 2,980 & 1,054 & 0,294 & 2,829 & 0,006 \\
\hline
\end{tabular}

Tabel di atas menunjukan nilai probabilitas signifikansi untuk semua variabel berada di bawah $0,05(<0,05)$ hal ini berarti bahwa secara parsial baik variabel Zfasilitas sekolah maupun variabel Zlingkungan sosial berpengaruh terhadap hasil belajar siswa. Masing-masing koefisien variabel ZFasilitas Sekolah dan Zlingkungan sosial bernilai positif sehingga dapat disimpulkan variabel ZFasilitas Sekolah brepengaruh positif signifikan terhadap hasil belajar siswa. Begitupun juga variabel Zlingkungan sosial berpengaruh positif signifikan terhadap hasil belajar siswa. Variabel moderating ABSX1_X2 memiliki nilai probabilitas di bawah 0,05. Temuan ini membuktikan bahwa variabel Lingkungan sosial 
adalah variabel moderating bagi pengaruh fasilitas sekolah terhadap hasil belajar siswa kelas XI dan XII IPS 1 MAN 1Madiun tahun ajaran 2014/2015.

\section{SIMPULAN DAN SARAN}

Berdasarkan hasil pengujian hipotesis yang telah diuji dengan menggunakan koefisien determinan, uji t statistic, dan uji $\mathrm{F}$ statistik menunjukkan bahwa fasilitas sekolah berpengaruh terhadap hasil belajar siswa kelas XI dan XII IPS 1 MAN 1 Madiun. Perpindahan lokasi sekolah MAN 1 Madiun berarti bahwa selain sekolah memiliki gedung baru, fasilitas-fasilitas yang ada di sekolah juga baru. Fasilitas sekolah ini memungkinkan siswa untuk lebih giat belajar hingga mencapai hasil belajar yang baik. Demikian juga dengan lingkungan sosial berpengaruh terhadap hasil belajar siswa. Lingkungan sosial yang baru bagi MAN 1 Madiun dimana letaknya dekat dengan Universitas Islam Indonesia Madiun sangat mendukung iklim belajar bagi siswa MAN 1Madiun. Iklim pendidikan yang kondusif telah terbentuk pada lingkungan tersebut.

Berdasarkan hasil uji nilai selisih mutlak dapat diketahui bahwa lingkungan sosial merupakan variabel pemoderasi bagi pengaruh variabel fasilitas sekolah terhadap hasil belajar siswa MAN 1Madiun. Hal ini bisa dijelaskan bahwa dengan fasilitas sekolah yang baru dan lebih memadai serta didukung dengan lingkungan sosial yang kondusif untuk belajar maka akan semakin mempengaruhi hasil belajar siswa.

\section{Daftar Rujukan}

Arikunto, Suharsimi. 2010. Prosedur Penelitian Suatu Pendekatan Praktik. Jakarta: PT. Rineka Cipta.

Djamarah, Syaiful Bahri dan Aswan Zain. 2008. Strategi Belajar Mengajar. Jakarta : Rineka Cipta.

Hidayat, Rahmat. 2013. Pengaruh Disiplin Dan Fasilitas Sekolah Terhadap Hasil Belajar

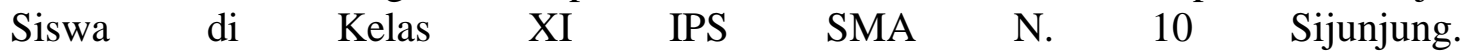
(www.lontar.net/red/531f067eof236a525sc33c49, diunduh pada 10 Maret 2015) .

Muhibbin Syah. 2012. Psikologi Pendidikan. Bandung : PT. Remaja Rosdakarya.

Mulyasa. 2011. Manajemen Berbasis sekolah, Bandung : PT. Remaja Prosda Karya.

Pakpahan, Haryadi. 2013. Pengaruh Fasilitas dan Lingkungan Belajar Terhadap Prestasi Belajar SMK Raksana 2 Medan Tahun Ajaran 2012/2013. http://www.google.com. Diunduh pada 9 Maret 2015. 
Permana, I Putu Raditiya Eka. 2014. Pengaruh Lingkungan Sosial Terhadap Hasil Belajar $\begin{array}{lllllll}\text { Siswa di Kelas XI IPS } & \text { SMA } & \text { N. }\end{array}$ (httpwww.google. comurlsa=t\&rct=j\&q=\&esrc=s\&source=web\&cd=5\&cad=rja\&uact= 8\&ved=0CEsQFjAE\&url=http\%3A\%2F\%2Fjurnal.untad.ac.id\%2Fjurnal\%2Findex.ph p\%2FGeoTadulako\%2Farticle\%2Fview\%2F2615\%2F1748\&ei=1099U9GMLY2E8g WwyYG4AQ\&us, diunduh 9 Maret 2015).

Priyatno, Duwi. 2009. Analisis Korelasi, Regresi dan Multivariate dengan SPSS.Yogyakarta : Gava Media.

Rusman. 2013. Belajar dan Pembelajaran Berbasis Komputer. Jakarta: Rajawali Pers.

Siregar, Syofian. 2011. Statistik Parametrik untuk Penelitian Kuantitatif. Jakarta : PT Bumi Aksara.

Slameto. 2010. Belajar \& Faktor - Faktor Yang Mempengaruhi. Jakarta: Rineka Cipta.

Sopiatin, Popi. 2010. Manajemen Belajar Berbasis Kepuasan Siswa. Bogor :Ghalia Indonesia.

Sugiyono. 2010. Metode Penelitian Pendidikan Pendekatan Kuantitatif, Kualitatif, dan R\&D. Bandung: Alfabeta.

Suprijono, Agus. 2011. Cooperative learning. Yogyakarta: PustakaPelajar.

Undang-undang Republik Indonesia No. 20 tahun 2003 tentang Sistem Pendidikan Nasional.

http://radityapenton.blogspot.com/2012/11/pendidikan-formal-informal-dan-nonformal.html 